\title{
CARACTERIZACIÓN DE LOS USOS DEL SUELO DE UN ESPACIO PERIURBANO DEL GRAN RESISTENCIA.
}

\section{SOILS-USE CHARACTERIZATION OF THE GRAN RESISTENCIA AND NEIGHBOURING AREAS}

\author{
Prof. en Geografía ALBERTO, Jorge Alfredo. \\ "Centro de Geociencias Aplicadas" \\ Facultad de Humanidades y de Ingeniería. \\ (3500) - Resistencia, Chaco.-(03722) 436298.
}

jaalberto@arnet.com.ar

RESUMEN: El presente trabajo hace referencia a un área del ámbito periurbano del Gran Resistencia localizada a $10 \mathrm{~km}$. al norte del mismo, atravesado por el río Tragadero y la ruta Nacional $n^{\circ} 11$.

El mismo en los últimos años presento fuertes cambios en relación al uso del suelo, debido a la presión de la ocupación y las problemáticas ambientales derivadas de ello; como el incremento en la degradación de las formaciones boscosas, la erosión de las cabeceras hídricas, la obstrucción de canales, la perdida de la capa fértil del suelo por erosión hídrica y eólica sobre superficies dedicadas a los cultivos; lo cual estaría acompañado por el desarrollo de bolsones de pobreza.

PALABRAS CLAVES: Espacio periurbano, Usos del suelo, Evolución, Condicionantes, Problemáticas

ABSTRACT: This paper deal with on a region located to $10 \mathrm{~km}$ northward of Gran Resistencia area (into its influence zone). The Río Tragadero river and the National Railroad $N^{0} 11$ cross the study area.

The area suported important changes during the last years. These changes were related to soil use because people ocupation pressure and related environmental problems caused by them.

A rapid increasing in deforestation woods processes, the aceleration head hidric erosion processes, the blocking of artificial canals, the lost of more richest soil beds due to hidric weathering and aeolian processes over agriculture areas are good examples to illustrate the problem.

These phenomena could be strongly related to human life degradation which are called as poverty handbags ("bolsones de pobreza").

KEY WORDS: periurban space - soils use - evolution - determinant factors - questions

\section{INTRODUCCIÓN}

En los últimos tiempos la preocupación por las cuestiones ambientales ha crecido considerablemente en todo el mundo; en especial los relacionados con el desarrollo de los sistemas periurbanos que crecen sobre el ámbito rural por la expansión de las márgenes de las ciudades en forma de "anillos" o por la extensión de "corredores", donde existe una compleja interface de construcciones edilicias con ambientes naturales y agropecuarios.

Uno de los problemas ambientales del Gran Resistencia es la diversidad de uso del suelo y la velocidad con el que este se da, aumentando las incidencias del mismo. Cada uso genera un impacto negativo o proceso degradante particular en el paisaje y en sus recursos (agua, suelo, aire, bosque, etc.) por la mala planificación del manejo de éstos.

En el escrito, se procura caracterizar y analizar la evolución de los usos del suelo del espacio periurbano del Gran Resistencia. Cabe agregar, que el presente trabajo está relacionado con proyectos que se vienen desarrollando en el Centro de Geociencias Aplicadas 
bajo la dirección del Ingeniero E. Popolizio, donde se procura unificar patrones de investigación referidos al impacto de la expansión urbana sobre terrenos de valor ambiental.

Teniendo en cuenta esta problemática se trabajó una metodología para el estudio del paisaje integrado, apoyada en una concepción geográfica y sistémica del paisaje. El método utilizado responde a la necesidad de analizar y caracterizar el proceso de urbanización incipiente; valiéndose para ello de bases cartográficas de síntesis e históricas, fotografías aéreas (1962 y 1977), imágenes satelitales (LandSAT TM 1997 y 1998) orientadas al uso de herramientas informáticas (CAD para diseño asistido y SIG para el análisis) que permitan analizar y evaluar las diferentes variables ambientales, para ello:

- Se desarrolló un modelo de tipo cualitativo que permitió identificar fortalezas, oportunidades, debilidades y amenazas que posee un área rural bajo la presión del crecimiento urbano.

- Se aplicó el mismo, al área de estudio, en diferentes cortes temporales referidos al proceso de ocupación para los años 1960, 1970, 1980, y 1990.

- A partir de su aplicación y del análisis de la evolución de la ocupación se identificaron las variables más significativas que controlan dicho proceso.

\section{ÁREA DE ESTUDIO}

A los efectos de la realización del presente trabajo se ha escogido como área de estudio (fig. 1) una superficie aproximada de $100 \mathrm{~km}^{2}(10 \mathrm{~km}$ de ancho, con sentido NE a SO, por $10 \mathrm{~km}$ de largo, con sentido NO a SE) localizada en el sector oriental de la Provincia del Chaco cruzada por el paralelo de $27^{\circ} 19^{\prime}$ latitud Sur y el meridiano de $58^{\circ} 59^{\prime}$ longitud Oeste.

La misma responde a un área del ámbito periurbano del Gran Resistencia localizado a unos $10 \mathrm{~km}$. al norte del mismo, atravesado por el río Tragadero y la ruta Nacional $\mathrm{n}^{\circ} 11$, en el cual se encuentran poblados como Colonia Benitez y Tres Horquetas, y parajes como Campo Rossi y El Tropezón.

Comprende parte de los Departamentos Libertad (Circunscripción II Sección A), San Fernando (Circunscripción II Sección A) y $1^{\circ}$ de Mayo (Circunscripción VIII, IX, X) según el catastro de la Provincia del Chaco.

\section{CONDICIONES NATURALES}

En detalle, el área de estudio es una planicie de acumulación que sustenta paleomodelos fluviales periódicamente inundables. Comprende específicamente parte de la cuenca del río Tragadero asentada sobre paleoderrames, cuyos rasgos dominantes son los continuos y progresivos procesos generalizados de erosión - sedimentación, complementados con la colmatación de biomasa muerta.

Todas estas condiciones dan lugar a una heterogeneidad interna que permiten determinar una diferenciación de zonas (fig. 2) subordinadas entre sí:

a) Zona de Paleoderrames: Son el resultado de la existencia de enormes paleoconoides aluviales del Bermejo que se superpusieron al modelado estructural, originando numerosos brazos divergentes con derrames laterales que se sobreelevaron de la planicie, sustentando en la actualidad formaciones boscosas y dejando entre ellos planicies embutidas.

En los sectores de terrenos elevados se encuentran formaciones boscosas altas cerradas con un importante desarrollo de suelo humífero y, bajas o degradadas en su periferia, donde el agua pluvial y fluvial influye algunos períodos del año; en consecuencia, con especies raquíticas y una capa de humus escasa.

b) Zona de Planicie Fluvial (o de Divagación): Es el valle o área de ambientes anegadizos retrabajados por el río Tragadero y sus afluentes dentro de los paleoderrames. En los mismos se observan la presencia de áreas boscosas atomizadas (con predominio de 
leñosas en las áreas más elevadas) que degradan periféricamente en abras, pudiendo estar asociadas a formaciones mixtas.

La escasa pendiente del terreno da lugar a un drenaje indeciso de los excesos hídricos pluviales, esto también incide sobre el Río Tragadero que tiene frecuentes desvíos en su recorrido dejando cauces abandonados denominados "madrejones" o lagunas "meandriformes". Dado el carácter arcilloso de algunas de ellas se tornan anegadizas y frecuentemente se cubren de vegetación de tipo palustres e hidrófilas (fisonomías de inundación).

Donde el derrame ha sido destruido en finas ramificaciones por la erosión, adopta un modelo de cañadas relacionadas a fisonomías de gramíneas, o bien pajonales, entre los que quedan islotes con fisonomías mixtas, representadas generalmente por extensos palmares de Copernicia alba.

c) Zona de Planicies Embutidas: La misma se caracteriza por tener terrenos encerrados por los diferentes regueros o paleoderrames. Dichos terrenos se comportan como cubetas donde el escurrimiento hídrico es lento y de permanencia temporal debido a la escasa pendiente.

Estas condiciones determinan la presencia de ambientes permanentes o periódicamente anegadizos (regidos por un desagüe lento), con especies vegetales adaptadas a estas condiciones de asfixia radicular, dando lugar a grandes extensiones de herbáceas o de sabanas.

Predominan gramíneas duras, de los géneros Elionorus, Andropogón Panicum, Paspalum y plantas herbáceas, especialmente compuestas y leguminosas, a los que se intercalan ambientes de menor extensión no inundables, ocupados por coberturas leñosas que se encuentran agrupadas en formaciones boscosas cerradas con abras de pajonales 0 higrófilas, que pueden estar asociadas a paleoformas fluviales actuales y eólicas.

\section{PROCESO DE OCUPACIÓN DEL ESPACIO}

El área de estudio esta sujeta a la influencia de antiguas colonias agrícolas - forestales como Colonia Benitez y Margarita Belén distantes a 17 y $21 \mathrm{~km}$. de Resistencia respectivamente y $7 \mathrm{~km}$. aproximadamente entre sí.

Las mismas han surgido a fines del siglo XIX a partir de la concesión de tierras a empresas para la fundación de colonias agrícolas y la explotación de los bosques de quebracho colorado, y con el tiempo, cultivos de algodón complementados con plantaciones de caña de azúcar. Esto trajo aparejado la presencia de fábricas dedicadas a la obtención de tanino, desmotado de la fibra de algodón y elaboración de melaza, azúcar y alcohol que respondían a capitales privados locales o extranjeros; por ejemplo se pueden citar las fábricas de tanino: Quebrachales Fusionados - Henningsen, Alsina; las desmotadoras: Alsina, Charleworth - Gabardini, Baldo, Delovo; el ingenio azucarero Svea, sumados a sistemas cooperativos como la desmotadora El Triunfo de Margarita Belén.

La lenta desaparición de fábricas por la poca rentabilidad económica de la explotación de los recursos naturales que brindaban materia prima, debido en gran parte al empobrecimiento en el número de ejemplares de importancia tánica de los bosques de quebracho colorado, al agotamiento de los suelos y, a un bajo precio en el mercado de los productos derivados, condicionó la crisis de estas colonias, con el consecuente estancamiento de su crecimiento y posterior proceso migratorio de su población hacia Resistencia.

A pesar de esta situación, en la década del 60 (fig. 3) nuevamente los cultivos de plantación como el algodón y tabaco se desarrollaron sobre la planicie embutida, en extensiones superiores a las 50 has. por productor. Estos cultivos respondían a planteos económicos para mercados extraregionales, los cuales se sustentaban a partir de políticas de potenciación por parte del gobierno y a cotizaciones imperantes en el mercado por esos años que los hacían interesantes. 
Debido a la baja tecnificación de los cultivos para su laboreo determinó la utilización de gran cantidad de mano de obra (peones golondrinas, cosecheros de la zona), que estableció un cierto aumento de la población en la zona (más de 2000 habitantes aproximadamente) y permitió el desarrollo de infraestructuras asociadas, como estufas o desmotadoras por medio de sistemas cooperativos.

Gran parte de la población (más del $80 \%$ ) se dedicaba a actividades agrícolas como peones, cosecheros y obrajeros en periodos cíclicos, y el resto se vinculaba a este sector productivo por prestación de servicios, tal es el caso de almaceneros, mecánicos, intermediarios, etc. Estas actividades se complementaban con la comercialización y trueque entre los habitantes de la colonia de gran variedad de productos avícolas, hortícolas y lácteos de producción doméstica.

El sector de empleados públicos, sólo se reducía a los ingenieros agrónomos del INTA Colonia Benitez, un medico y enfermera de la única sala de primeros auxilios, a los docentes de las escuelas $\mathrm{N}^{\circ} 10, \mathrm{~N}^{\circ} 36$ y $\mathrm{N}^{\circ} 4$, a la policía provincial y empleados municipales, sumado a un Juez de Paz con su respectivo secretario (que en la actualidad siguen desempeñando sus cargos).

En la década del $\mathbf{7 0}$ (fig. 4) se profundiza la crisis en el sector productivo primario, específicamente en los pequeños productores lo que obliga al abandono de sus predios y reconversión hacia el sector ganadero y sus derivados.

Esto determina una acelerada implantación de forrajeras (sorgo granífero) complementado con maíz dando lugar al crecimiento descontrolado de la población de ciertas especies de animales, como las cotorras (Myiopsitta monacha) que se convierten en nuevas plagas para dichos cultivos.

A pesar de la crisis planteada, se mantienen la superficie cultivada de algodón y tabaco en los grandes predios a los que se suman las parcelas dedicadas a forrajeras. Paralelo a esto, también se llevan adelante actividades de forestación con especies como eucaliptos y pinos a partir de políticas incentivadas por el gobierno provincial y nacional que quedarían sin efecto en la década del 80.

Por esta época, comienza a desarrollarse sobre la planicie fluvial, en proximidades del pueblo, un sistema de producción hortícola sin mucha tecnificación. Esta situación junto con el reparto familiar por herencia de lotes determina un alto parcelamiento de suelos productivos con la consecuente sobreexplotación y agotamiento de dicho recurso.

También existe un aumento de la deforestación, debido en un principio a la extracción de especies de importancia económica como se vio en los años 60 y luego, con el tiempo se fueron transformando las superficies boscosas en grandes extensiones herbáceas y sabanas arbóreas con fines ganaderos; cuyas pasturas, en gran parte, estuvieron sobreexplotadas con una fuerte degradación del suelo y su cobertura vegetal.

En este período se suman servicios e infraestructura como:

- Red de agua potable domiciliaria, dentro del pueblo, a partir de la construcción de una planta potabilizadora por parte de Sameep, basada en un sistema de bombeo y potabilización de agua subterránea y posterior distribución.

- Teléfono público a partir de una estación de la empresa estatal ENTEL y algunos teléfonos domiciliarios conectados a una línea tendida desde Resistencia.

- Se lleva adelante una red de electrificación sobre la ruta 11 hacia Margarita Belén que no beneficia a todos los vecinos debido a su alto costo de conexión a este servicio.

- El resto de los servicios se mantienen en las mismas condiciones que la década anterior.

A mediados de la década del $\mathbf{8 0}$ se realiza el acceso pavimentado a Colonia Benitez que, junto con la construcción de la escuela secundaria (ENS N ${ }^{\circ} 79$ San Francisco Solano), 
significó un cambio trascendental en el desarrollo de la comunidad, ya que en los últimos años se había acentuado el proceso migratorio de población joven a Margarita Belén y a la ciudad de Resistencia por la inexistencia de formación media, a lo que se sumaba la limitada posibilidad de trabajo en las adyacencias de la colonia. También se lleva a cabo la construcción y remodelación de dos escuelas primarias como la $N^{0} 181$ Paraje Tres Horquetas (sobre el acceso al camino pavimentado de Colonia Benitez) y la № 4 del Paraje El Tropezón.

Además, la existencia del acceso pavimentado permitió el flujo continuo de vehículos con productos agropecuarios frescos (avícolas, hortícolas y lácteos de elaboración doméstica) para su comercialización, o el movimiento pendular hacia Resistencia de población que se desplazaba para trabajar en actividades terciarias o realizar estudios superiores (tanto terciarios como universitarios). A esto se suma el aumento de horarios de líneas de autobuses, en especial el surgimiento de líneas interurbanas que favorecieron el movimiento pendular de la población entre Colonia Benitez, Margarita Belén y Resistencia.

También en este período se comienza la construcción de barrios de viviendas dentro de los pueblos, con facilidades para su adquisición. Situación que con el correr del tiempo se acentúo con nuevos planes de viviendas del Fonavi, Banco Hipotecario y sistemas de autoayuda a partir de subsidios brindados por el gobierno de la provincia del Chaco.

Como limitante a la situación antedicha se puede citar la inexistencia de un sistema de cloacas dentro del pueblo (específicamente dentro de los nuevos barrios de vivienda); para solucionar dicho problema debieron valerse de un mayor número de pozos negros, o ciegos, para evacuar los efluentes domiciliarios con la consecuente contaminación de las napas freáticas. La inutilización de estas como fuente de agua para consumo de un sector de la población sin beneficio del servicio de la red de agua potable, significó la instalación de canillas públicas o de cisternas de agua abastecidas por la municipalidad.

Además, gran parte de estos barrios fueron construidos sobre bajos ubicados al noreste del pueblo. El relleno de los mismos determinó la limitación del escurrimiento e endicamiento del excedente hídrico resultantes de las precipitaciones, inundando terrenos que no sufrían estas limitaciones.

La instalación de hornos por parte de dos empresas (Cerámica Paraná y Nanda) para la fabricación de ladrillos y derivados, sumados a la presencia de diferentes "ladrillarías" (hornos artesanales de ladrillos) debido a una fuerte demanda para la construcción incipiente dentro de la colonia (barrios de viviendas o construcciones particulares) como en el Gran Resistencia, determino una sobreexplotación del bosque y la sabana arbórea por la obtención de leña para ser utilizado como combustible de estos.

En este período se lleva adelante un fuerte proceso de electrificación rural por parte del gobierno provincial, Secheep y los vecinos de la colonia. La red se extendió en diferentes tramos hacia el Paraje El Tropezón, Tres Horquetas y Campo Rossi; también se realizó un tramo hacia Puente San Pedro que beneficio a Costa Iné.

Esta inversión fue acompañada por la apertura y mantenimiento de caminos y sistemas de desagües (como canales, alcantarillados, puentes, etc.) por parte de los "Consorcios Camineros" (asociaciones vecinales bajo la dirección de Vialidad Provincial) que al facilitar las comunicaciones permitió una mayor posibilidad de instalación o permanencia de población en el lugar por un lado y movimientos de bienes por otro. Como ejemplo se puede tomar la apertura de caminos hacia la ruta 11 y Puerto Tirol dentro del paraje denominado Campo Rossi, a lo que se sumó el proceso de electrificación; ambos emprendimientos posibilitaron la aparición de nuevos asentamientos de familias dentro de tierras fiscales a partir de organizaciones no gubernamentales como Incupo y Caritas.

También existió una reconversión marcada en lo que se refiere a la producción agrícola, donde el cultivo del algodón y el tabaco son reemplazados por la horticultura, a partir de pequeñas empresas familiares en predios donde se lleva una explotación de tipo intensiva y cierta tecnificación (bajo cubierta y riego a esparción) en las proximidades de espejos de agua dulce. 
A fines de la década del 90 (fig. 5) la construcción de la Defensa Norte en la zona en el Paraje El Tropezón, dentro del área de estudio, dió lugar por un lado a un fuerte parcelamiento de tierras para su venta, y por otro, a una revalorización de las mismas sujeto a la cotización de la oferta y la demanda.

La incipiente construcción de viviendas no sólo como residencias permanentes, sino también con fines de recreación y esparcimiento, ha sido acompañado por una fuerte transformación del paisaje debido a la generación de praderas artificiales y bosques monoespecíficos de especies exóticas; lo que evidencia una revalorización de las tierras, ya no por su valor o aptitud productiva, sino por su valor fiscal o urbano.

Estas tierras adquieren mayor cotización en primer lugar por su proximidad al casco urbano de Resistencia, al pueblo o a la ruta 11, en segundo lugar por su facilidad de acceso y la presencia de electrificación, y finalmente, por la existencia de espacios verdes con bosques nativos o raleras y la proximidad al río o algún espejo de agua, o terrenos con una moderada permanencia de agua.

En consecuencia, en la actualidad se observa en la zona un elevado parcelamiento de tierras en dos ejes perpendiculares entre sí. El primero acompaña la ruta 11, pudiendo reconocerse núcleos de asentamiento que superan los 8 habitantes por hectárea, la mayoría en la margen derecha. El segundo acompaña el río Tragadero con más de 6 habitantes por hectárea y circunvala hasta superar el ejido municipal de Colonia Benitez con una densidad que oscila entre los 6 y más de 10 habitantes por hectárea.

El Paraje el Tropezón, al igual que sus alrededores, presenta un cierto estancamiento en relación con dicho parcelamiento y crecimiento poblacional. Esto se debe en gran parte al elevado costo fiscal e impositivo de las tierras por estar, como lote rural, dentro del ejido municipal de Resistencia, a diferencia del resto de tierras que pertenece a Renta de la Provincia, cuyo aporte en impuestos es mucho menor.

A partir de lo detallado con anterioridad, en el paraje se advierte que existe una mayor cantidad de loteos de tierras del que aparece en los planos catastrales. Estos loteos encubiertos responden a una evasión impositiva por parte de sus propietarios al municipio de Resistencia. Es decir, los títulos de propiedad del parcelamiento de tierras inferiores a 5 has. con fines inmobiliarios o de urbanización son inscriptos a nombre de una o dos personas cuando en realidad, en la mayoría de los casos, superan esa cifra, pudiendo llegar a encotrar más de diez propietarios en un predio inferior a las 5 has.

Cabe agregar que hasta 1985 la ocupación y parcelamiento de tierra con fines urbanos se realizo sobre la ruta 11 y la "vieja entrada" a Colonia Benitez. A partir de 1985 hasta 1998 aproximadamente, la tasación inmobiliaria se mantiene por su proximidad al Gran Resistencia, pero los mayores loteos y procesos de compra y venta se traslada hacia la nueva entrada a Colonia Benitez, también conocida como "Acceso Pavimentado" a más de $7 \mathrm{~km}$. de la "vieja entrada".

La zona de antiguo acceso o del Tropezón nuevamente vuelve a tener auge a partir 1998 cuando se inician las obras del Plan de Defensa, con la apertura de caminos donde se profundizan los fraccionamientos de tierras, muchos de ellos evadiendo el fisco como se comento en párrafos anteriores.

\section{PROBLEMÁTICAS RESULTANTES}

La ocupación progresiva se ha realizado sin que se tuvieran en cuenta, por desconocimiento, la susceptibilidad y tendencia natural del sistema sujeto a estudio. Como resultado de lo expresado han tenido y están teniendo lugar modificaciones muy significativas, que han ido aumentando paulatinamente, y podrían verse aceleradas si no se toman una serie de medidas de protección. Se concluye que: 
- El primer problema resulta del talado de la cobertura boscosa para el desarrollo de la actividad agrícola, que frecuentemente se inicia a lo largo de los paleocauces para terminar ocupando todo el espacio. Ello trae aparejado un aumento de las posibilidades de los procesos seudokársticos.

- El quitado de la cobertura arbórea favorece la remosión eólica, que se hace tanto más intensa cuanto mayor es el talado, los incendios (naturales o artificiales) y la roturación del suelo.

- La sobrecarga animal, influyó también en los bosques al destruir allí las gramíneas, vegetación herbácea y arbustiva del sotobosque, lo cual sumado al pisoteo del ganado, contribuyó a acelerar los procesos de descamación y destrucción del suelo

- Los procesos de voladura y decapitación de suelos son bastante comunes, especialmente si se tiene en cuenta que la acción mantiforme del agua tiende a acentuarse e incluso a degenerar por la pendiente en subtipos filetiforme o surcoico.

- La acentuación de la tendencia natural (a partir de la aceleración de la erosión de cabeceras hídricas, las obstrucciones en las desembocaduras, acumulación en las depresiones inundables) como consecuencia de las diferentes obras de manejo hídrico que se han construido en el área, sin ningún plan director que integre los procesos económicos de explotación o de ocupación del espacio y, la preservación de los recursos naturales por medio del manejo sustentable.

- Otro problema que podemos mencionar es semejante al anterior y está originado por las vías de comunicación. Estas al ser trazadas sin tener en consideración el sistema de escurrimiento, repetidamente lo interfieren como verdaderos muros de embalse, causando nuevas áreas inundables e incluso transfluencias.

- Finalmente, el incremento de habitantes en la zona determinó la aparición de núcleos poblacionales con fines residenciales y de esparcimiento. Esto significó un excesivo parcelamiento inmobiliario de tierras y una artificialización de los mismos a partir de una tala selectiva de cobertura vegetal e implantación de otras, con la introducción de especies exóticas, a lo que se suma una alta explotación y contaminación de napas freáticas condicionada por la falta de servicios básicos.

\section{CONCLUSIONES}

El proceso de ocupación genero una profunda alteración ambiental en el área de estudio que se observa y comprueba a través de un conjunto de casos, como la perdida del control de determinadas poblaciones y de procesos morfogenéticos que han cambiado totalmente la dinámica y comportamiento de evolución del espacio.

Todo estos procesos que tienen una secuencia lógica de cambio de propiedades, presentan las siguientes características ambientales o acciones observables:

- Pérdida de ciertos balances poblacionales y explosión de muy pocas especies, denominadas incrementadoras o invasoras; a los que se suman profundos cambios de la estructura de la vegetación, tanto la vertical como la horizontal, acompañados por la pérdida de la riqueza específica, con extinción local de varias especies.

- Pérdida del recurso suelo por mal manejo agrícolaganadero y excesivo parcelamiento inmobiliario, lo que genera la acentuación de procesos seudokársticos con incisión lineal en los paleoderrames y captura de redes.

- Baja integración entre lo natural y social como:

- Especulación inmobiliaria.

- Asentamientos de origen ilegal que aumenta el mal uso de los recursos del ambiente.

- Concentración de población en áreas inundables.

- Bolsones de pobreza debido a la escases de posibilidades laborales y mal aprovechamiento de recursos existentes.

- Densificación urbana por éxodo rural de zonas aledañas y en consecuencia deficiencia de servicios e infraestructuras.

- Incremento de la inseguridad (bienes y personas) a lo que se suma la confrontación entre vecinos por diferencias de pautas culturales o de costumbres. 
- Alteración de la forma de vida de la población y de las cualidades espaciales del área de estudio.

Finalmente cabe agregar que el fenómeno de expansión urbana es en la actualidad un problema que es producto de un limitado planeamiento en cuanto a usos y ocupación del suelo, reglas de mercado, políticas impositivas poco justas y la superposición de injerencias en estructuras gubernamentales. Este proceso puede tener un impacto relativo, fácil y económicamente solucionable, aunque en verdad implica altos costos asociados. Uno de ellos se relaciona con los elevados montos que implica llevar servicios a áreas de expansión no planificadas, lo que no ocurre dentro de áreas que si cuentan con esta alternativa. Sin embargo, un tema que se destaca por sobre los otros, es el impacto que genera el crecimiento urbano sobre espacios verdes, tierras de valor ambiental y agrícola, principalmente cuando los centros urbanos se ubican en lugares topográficos poco recomendables de alto riesgo natural como ámbitos sujetos a inundación.

Para ello, se debe profundizar el estudio de las variables condicionantes del proceso de ocupación de tal modo que permita evaluar alternativas apropiadas a la zona, ya que la posibilidad en el futuro de que se intensifique la ocupación con fines urbanos de terrenos productivos desde el punto de vista agrícola o con situación de riesgo de inundación, hace a la necesidad del planteo de un plan rector que permita un mayor control.

Este plan deberá contemplar la posible planificación de un crecimiento urbano sustentable, en equilibrio con el entorno y con las características sociales y culturales, para ello tendrá que proponer diversas políticas que permitan regular estos procesos con el fin de alcanzar los objetivos públicos. Además, dichas políticas tendrán que centrarse en opciones de usos del suelo y alternativas de zonificación, que determinen y delimiten áreas de reserva de espacios verdes con el fin de contribuir el bienestar social.

\section{BIBLIOGRAFÍA}

- Administración Provincial del Agua (APA) (1998). "Restricciones al uso del suelo". www.apa.gov.ar

- ALBERTO, Jorge Alfredo (2001-2002) "Problemáticas ambientales resultantes de la ocupación de planicies de inundación. Caso Area Metropolitana Gran Resistencia" SGCYT/UNNE. Inédito.

- FERNANDEZ, Roberto (1998). "Componentes teóricos y metodológicos de la Gestión Ambiental". Documento de la Maestría de Gestión Ambiental. UNNE. Rcia. Chaco.

- Ministerio de Obras Publicas y Transporte. (1992.). "Guía para la elaboración de estudios sobre el medio físico. Contenido y metodología”, Madrid (España).

- MORELLO, Jorge (1983). "El Gran Chaco: el proceso de expansión de la frontera agrícola desde el punto de vista ecológico - ambiental." (391 - 396 pp.) En: Expansión de la frontera agropecuaria y medio ambiente en América Latina. De. CIFCA, Madrid, (España). 427 pp.

- POPOLIZIO, E. y SERRA, P.Y. (1980) "Bases fisiograficas para el manejo de los recursos hídricos en un sector de la llanura chaqueña" en Rev. Geociencias n IX. C.G.A. UNNE. Rcia. Chaco. pp. $43: 64$

- POPOLIZIO, Elíseo (1982). "La geomorfología en los estudios ecológicos de la llanura" en Geociencias XII. Publicación del Centro de Geociencias Aplicadas. U.N.N.E. Rcia. Chaco.

- POPOLIZIO, Eliseo (1989). Algunos elementos geomorfológicos condicionantes de la organización espacial del NEA. Geociencias XVII. Centro de Geociencias Aplicadas. Facultad de Ingeniería y Humanidades. UNNE. Resistencia. Chaco.

- SCORNIK, Carlos (1998). "Diagnóstico Expeditivo AMGR".- Ministerio del InteriorPrograma de Protección Contra Inundaciones (P.P.I).-SUPCE- Convenio BIRF- Provincia del Chaco 364p. 
Gevista Geográfica Digital . IGUNNE. Facultad de Humanidades. UNNE. Año 1- No 1

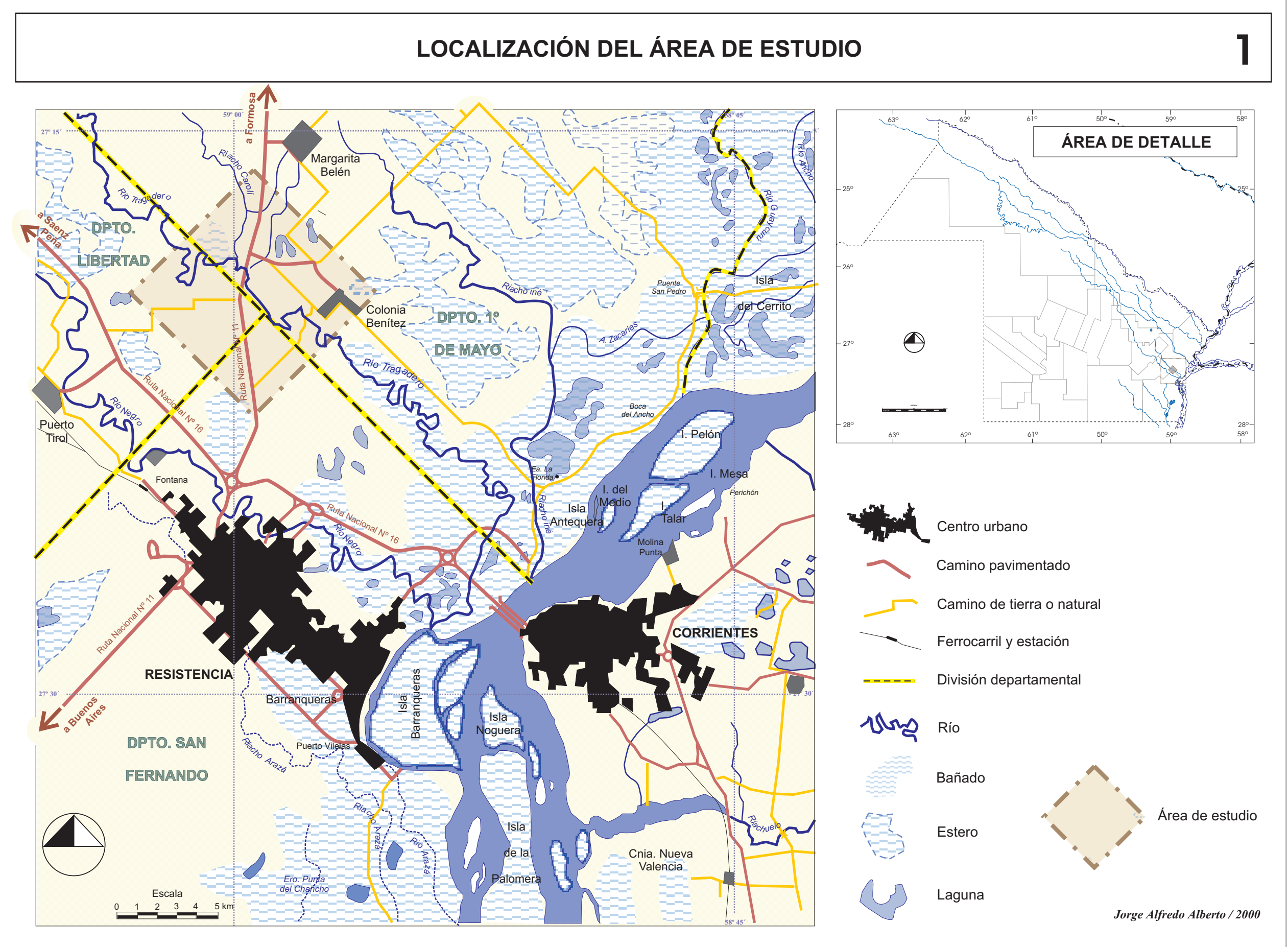



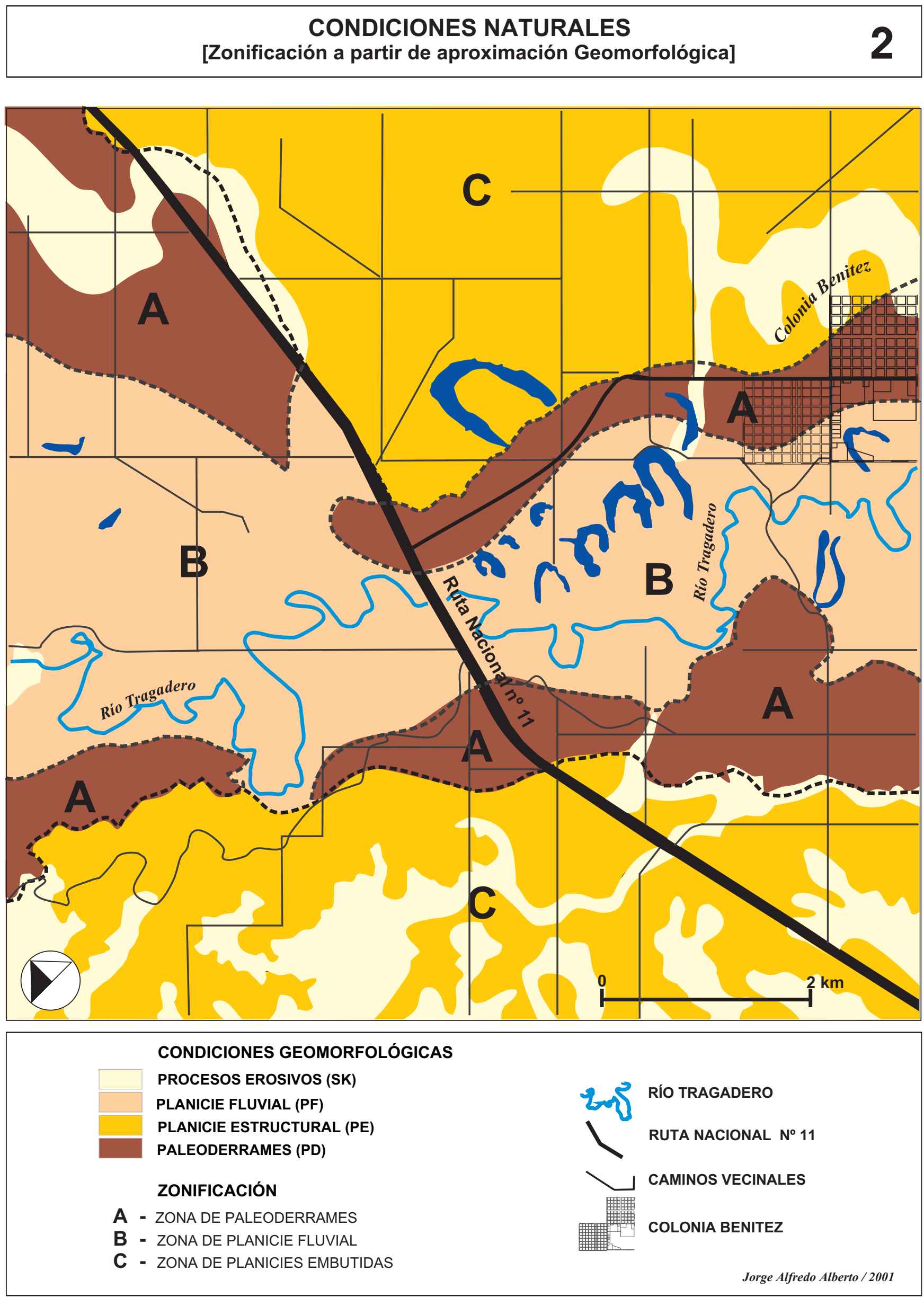
Revista Geográfica Digital . IGUNNE. Facultad de Humanidades. UNNE. Año 1- No 1 Marzo - Abril 2004. ISSN 1668-5180 Resistencia, Chaco

USO DEL SUELO - 1962

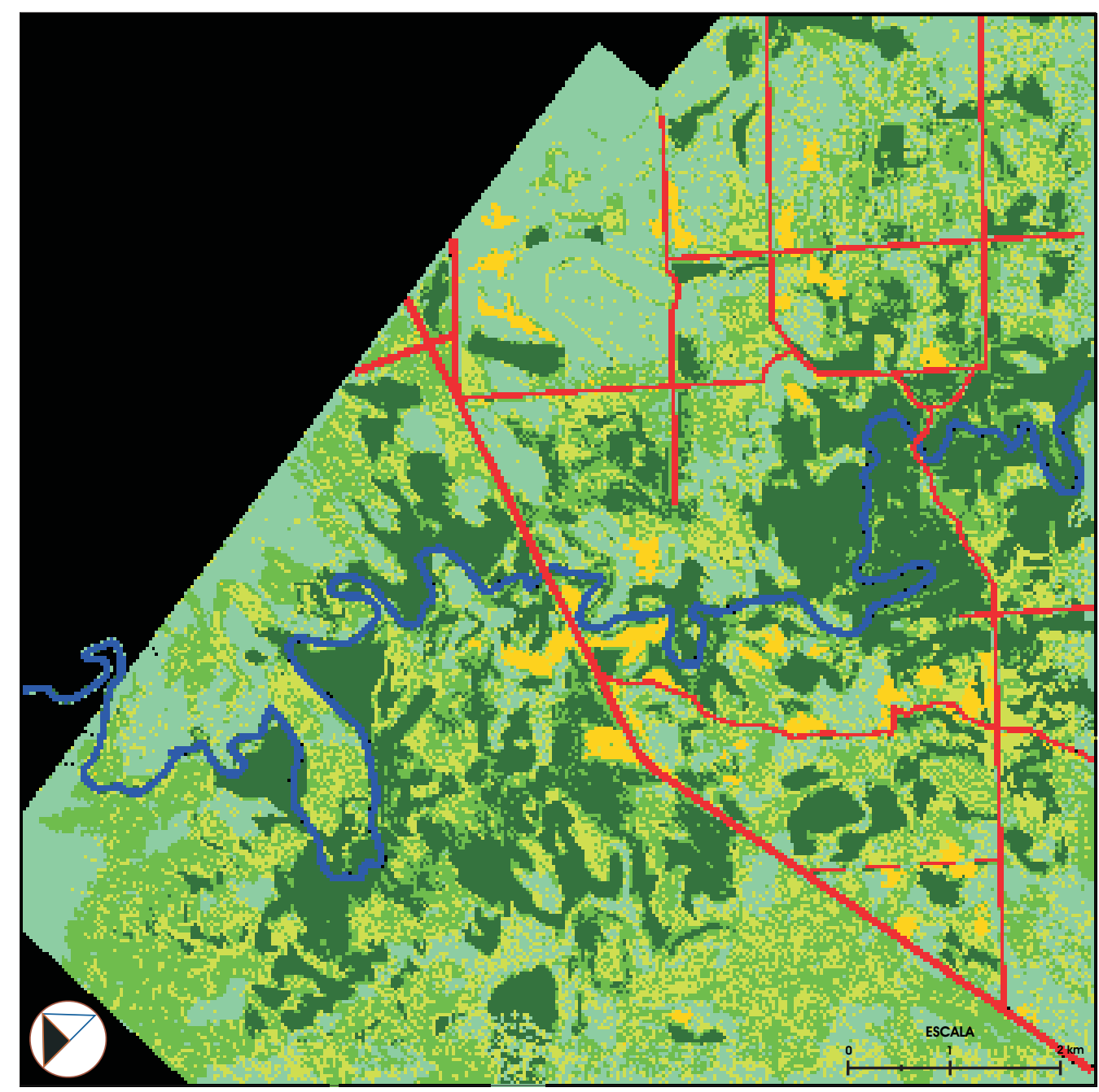

USO DEL SUELO BASE (ERROR)
FORMACIÓN BOSCOSA CERRADA
SABANA ARBÓREA

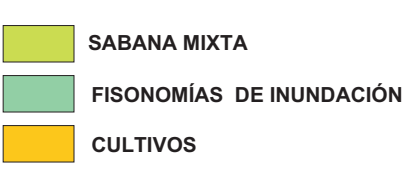

2or
DISTRIBUCIÓN DE LOS USOS SOBRE EL TOTAL

DEL ÁREA DE ESTUDIO (en relación al $\mathbf{N}^{\circ}$ de celdas, has, \%)

Referencia

Base (error)

Formación Boscosa Cerrada

Sabana Arbórea
Sabana Mixta

Fisonomía de Inundación

Cauce

Cultivos

Total

Código $\mathrm{N}^{\circ}$ de celdas

$\begin{array}{ll}\text { Sup. has. } & \text { Sup. } \% \text {. } \\ 2242.05 & 22.421 \\ 1768.6 & 17.686\end{array}$

$\begin{array}{lll}224205 & 2242.05 & 22.421 \\ 176860 & 1768.6 & 17.686\end{array}$

$206024 \quad 2060.24 \quad 20.602$

$\begin{array}{lll}137883 & 1378.83 & 13.788\end{array}$

$\begin{array}{lrr}193895 & 1938.95 & 19.390\end{array}$

\begin{tabular}{lrr|r}
19819 & 198.19 & 1.982
\end{tabular}

$24798 \quad 247.98 \quad 2.980$

$\begin{array}{lll}24798 & 247.98 & 2.480 \\ 16516 & 165.16 & 1.652\end{array}$

$\begin{array}{llll}\text { Total } & 1000000 & 10000 & 100\end{array}$
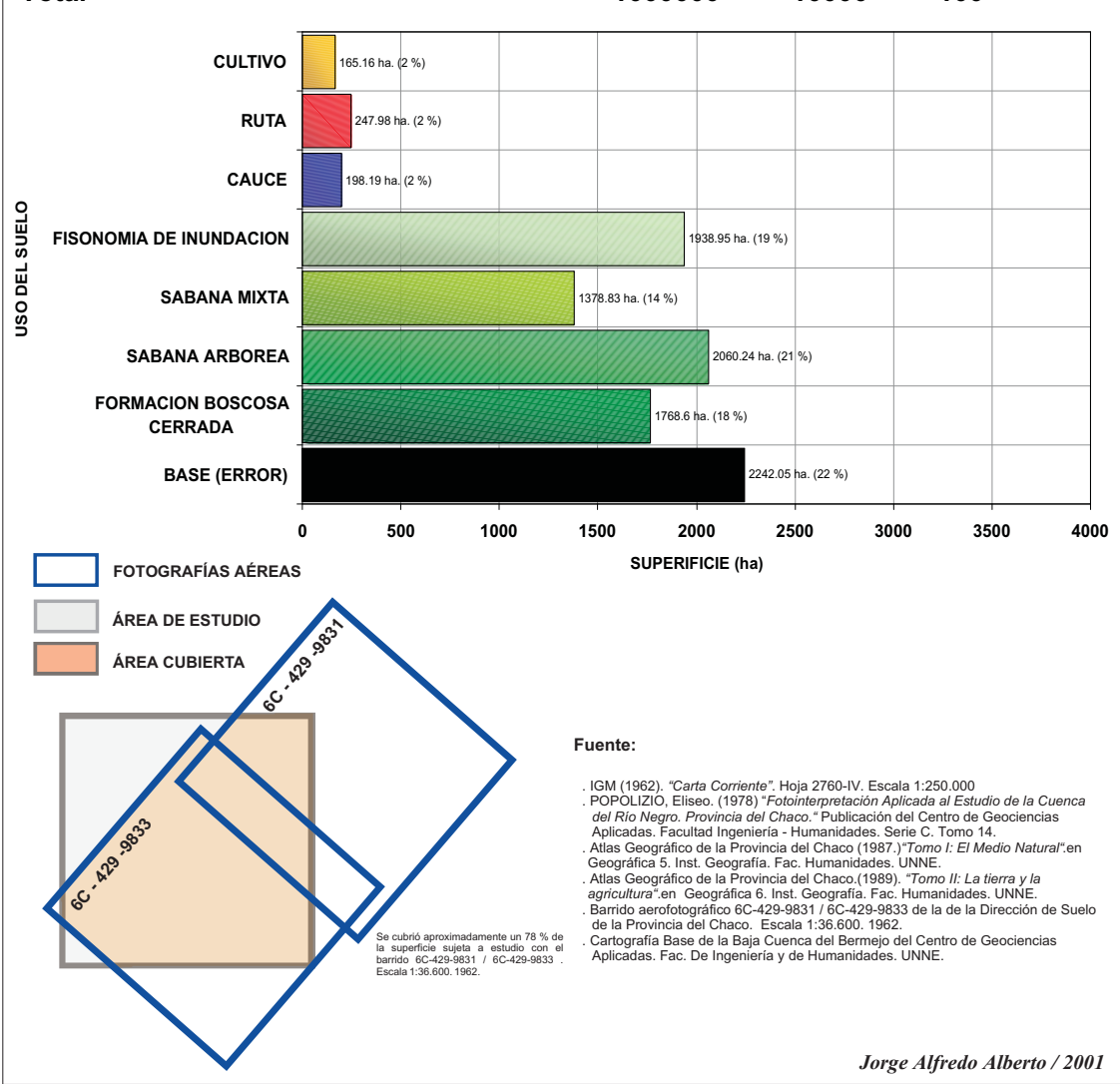

Fuente:

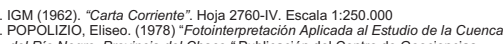

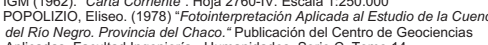

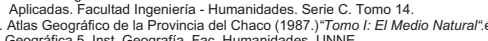

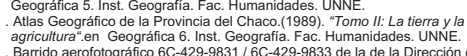

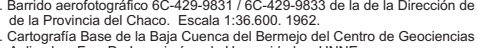

Río TRAGADERO

RUTA Y CAMINOS 
Revista Geográfica Digital . IGUNNE. Facultad de Humanidades. UNNE. Año 1- № 1

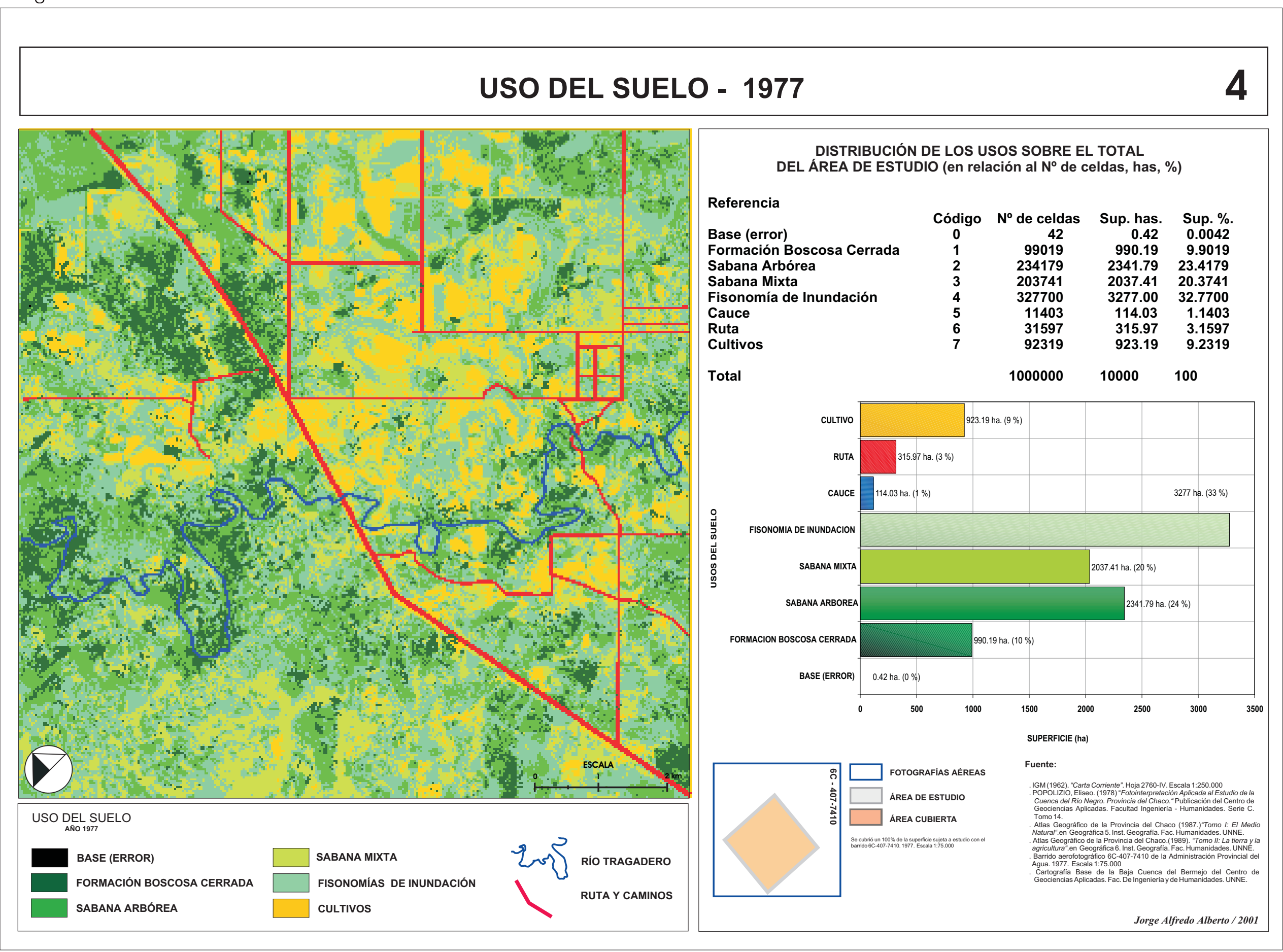




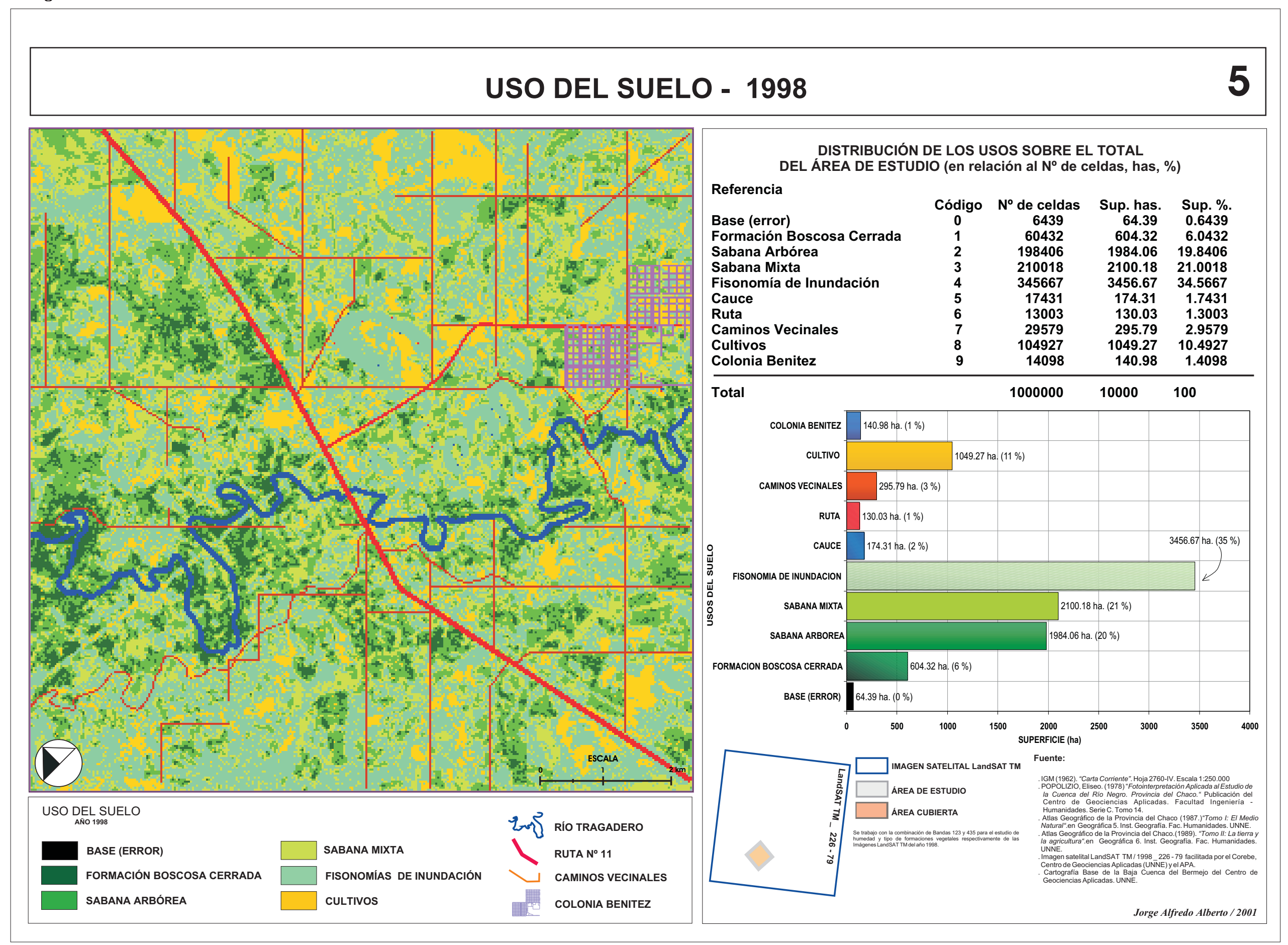

